\title{
Educational role of language - past, present and future visions?
}

\author{
Elena Kováčiková \\ Constantine the Philosopher University in Nitra, Slovakia, Faculty of Education; ekovacikova@ukf.sk
}

Languages do not serve as communication means only anymore as above its fundamental function they open the doors and reveal a lot aboutthe world of linguistics, culture, sociology, psychology, neuroscience, literature, mother tongue acquisition and interconnections of different existing and nonexisting languages at various layers and through different aspects.The conference under the title 'Educational Role of Language' is held in Craiova, Romania on 17-18 June 2019. It is the fourth time when the people-experts working, studying, exploring or investigating the language in the fields of schooling institutions or research centres focusing onforeign or native language acquisition, teaching and learningand literary research, gather in order to discuss their academic success, issues and challenges. The previous three meetings encompassed thelanguage as a common denominator of all the discussions, plenary talks, and group sessions with the promising potential for international cooperation in further research. An idea that sparkled on the meetings was developed into the ERL association as a proof of the thoughtful and meticulous work of the organizers and initiators. This paper recalls the previous work and achievements of the ERL conferences held in the university premises as well as the present state and future directions of the successful series, ending with the definitions of ERL association.

Educators, teachers, students, linguists, experts from the organizing country and abroad assembled in the premises of the University of Gdansk in Poland on 9-10 June 2016 with the aim to take their important part in the 1st International Pedagogical and Linguistic Conference ERL - Learn to speak, speak to learn. As the aim of the ERLis to bring together academics combining language and educational science, "following the rationale of the 'linguistic turn'of studying how languages shape understanding of the world and people's functioning in it" (Institute of Pedagogy, 2014 online), this direction was consistently followed. After the official opening and welcoming the participants by the university authorities, prof. Anna Wasilewska and Dr. Michal Daszkiewicz on behalf of the organizers introduced the idea of the conference. The plenary session began with the contribution of the professor Wenzel from the University of Gdansk titled with Predictions on General Education and the role of language in it, followed by prof. Filipiak, Dr Clegg from England, Prof. Philpott from Leeds Becket University, Dr. Sousa from Portugal and prof. Capraru from Romania. Their talks ranged from cultural, educational, parenting and psycho- and neurolinguistics aspects with the language as a common feature.Prof.Wisniewska-Kin from Poland discussed the cognitive matrices of children when speaking, followed by the talk of prof. Kusiak-Pisowacka and Prof. Gmerek on reading and translation. The plenary talks concluded the contribution of prof. Kuszak talking about the role of language in the literature. Afternoon group sessions were divided into four themes according to their orientations. Within two days, 48 contributions were presented, discussed and connected and in 4 potentials of the joint international projects, namely Potential of Language for General Education, Language Activity of Children, Personal Experiencing the Language, and Linguistic Matrixes of Reality Interpretation(Cf. http://www.educationalroleoflanguage.ug.edu.pl/1st-conf-programme-0, online). To sum up, the academics from 15 countries in June 2016 with ERL I commenced the journey of the following gatherings.

A year later, the second International Pedagogical and Linguistic Conference under the heading 'Educational Role of Language - Social and Cultural Determinants (ERL II) was held in the same academic ground of the University of Gdansk on 12-13 June 2017. The main question on how is the educational role of language determined socially and culturally was supported with a number of partial queries determining particular themes that appeared in the previous conference. These questions enhanced deeper understanding and closer insights into the research problems comprising language in different 
contexts, i.e. language potential for general education, language activity of children, personal experiencing of language, and linguistic matrixes of reality interpretation. The exemplary questions under the particular themes helped the participants to fit more precisely into the directions of language research. Thus, the main concepts apart from the educational and linguistic fields were broadened with the sociolinguistic and anthropologistic views that were bound with the language.After the official gathering and opening talks by the university authorities, the talks presented by prof. Anna Wasilewska and Dr. Michal Dszkiewicz from the University of Gdansk were delivered. Prof.DeborazZuercher from the University of Hawaii at Manoa explained the situation of multiligualism in Hawai. Then, Dr. Roderick Nielsen from Deakin University in Australia was talking about 'demystifying' the language in teacher education. It was followed by Isaac Calvert from the University of Oxford discussing teaching and learning Hebrew language. That day the round of the overseas plenary speakers was closed with the contribution of Janice Myck-Wayne from the California State University on special need learners. Prof. Kusiak-Pisowacka from the University in Krakow discussed the intercultural competences in a foreign language classroom. The following day, the plenary session offered knowledgeable presentations by Melanie Aplin and Leela Koenig from the English-Speaking Union on oracy and Dr.Chizuko Suzuki from Japan on still resonant topic of critical thinking in education. This gathering was special because in the second year of ERL existence the two on-going projects initiated in the ERL I were introduced. The first one was carried out under the title Oracy in the school culture and it was developed in the cooperation of prof. Otilia Sousa and Dalila Lino from the Polytechnic Institute from Portugal and Dr. Magdalena Waswrzyniak-Sliwska and MArtynaPiechowska from the University of Gdansk, Poland. The second project born under the ERL cooperation was a comparative study on 'Productive language development in L1 and L2 among 9-year old pupils from teacher's perspective in Iceland and Poland' presented by its coordinator Paula Budzynska from the Copernicus University in Torun and Sigriðurólafsdóttir from Iceland. The last two contributions proved meaningfulness and purposefulness of the ERL meetings resulting in fruitful international cooperation in research. Within the two days, forty contributions were presented in the afternoon group sessions divided into the four rounds according to their fields of interests. It is necessary to add that thanks to the appropriate number of attendees it was possible to make closer connections based on the professional interests and therefore the ideas for the further cooperation were developed later on. The number of participating countries reached 20 in the ERL project proposals.

The venue of the third International Pedagogical and Linguistic Conference 'Educational Role of Language. How do we understand it?' was organized under the auspices of the Lithuanian University of Educational Sciences in Vilnius within 14-15 June 2018. The international focus of the conference was broadened by the partnering co-organising universities, namely University of Gdansk, Poland; University of Craiova in Romania, and the Constantine the Philosopher University in Nitra, Slovakia. After the official opening of the conference by the university authorities, the plenary session was commenced by a cross-country analysis presented by Alina Reșceanu Monica Tilea from the University of Craiova, followed by the role of language learning from the eyes of Cristina Berry from the Georgetown University, USA. The contribution of the ERL founder Michal Daszkiewicz revealed the ERL developments, scopes and studies. The representative of the University of Hamburg, Helmut Johannes Vollmer discussed the language of schooling directed to thinking and interaction. The other day, the plenary session continued with the contribution presented by EglePetroniene from the Lithuanian University of Education Sciences and the view on the amplitude of language education referred to CEFR, followed by BranwenBingle from the University of Greenwich on the personal construct theory to critical literacy and language analysis, and it was concluded by the Greek team of experts from the University of Western Macedonia talking about students' attitudes towards foreign languages and multilingual learning in Greece and Cyprus. As for the group sessions, similarly as during the previous years, 44 papers were presented in the four sections defined by the different views on the language. These were language beliefs or what we think of language, language activities or what we do with language, language experience or how we feel about language and language matrices or how we perceive through language. 
All in all, within 3 intensive years of annual ERL meetings, the participation circle of 92 academics from 26 states (Cf. http://educationalroleoflanguage.ug.edu.pl/erl-network-0, available online) has been created and several projects have been founded. Year 2018 was special with the announcementand the birth of the ERLA - as the International Association for the Educational Role of Language created on the basis of the ERL network. The intention of the ERLA is to 'bridge the gap between linguistic and educational studies. '(Cf. http://educationalroleoflanguage.org/, availableonline) with its mission to broaden the issue of the language through all aspects internationally through networking and setting up the grounds for meaningful studies and research. Only thus, the role of language can be enhanced and comprehended to its full extent.

The distinguished French linguist and psychoanalyst Julia Kristeva concludes her knowledgeable book saying humbly: "that still unknown object-language." (1989, p. 329). Not doubting her statement we truly believe that annual ERL conferencesand active work of ERLA association can bridge the gaps and find the answers and fundamental concepts for that 'unknown' in the role of the language.

\section{Acknowledgements}

This paper was funded by the Cultural and Educational Grant Agency of the Ministry of Education, Science, Research and Sport of the Slovak Republic (KEGA 006UKF-4/2017).

\section{References}

Institute of Pedagogy, 2013-2014, Educational Role of Language. http://www.educationalroleoflanguage.ug.edu.pl/aims-projects.

ERLA. Available online on http://educationalroleoflanguage.org/erla-membership/.

Kristeva, J. (1989). Language the unknown. New York: Columbia University Press.

Acknowledgements: The text was funded by the Cultural and Educational Grant Agency of the Ministry of Education, Science, Research and Sport of the Slovak Republic (KEGA 006UKF/2017). 